\title{
Endoscopic treatment of a Zenker's bilocular diverticulum with cap and TT knife catheter
}

\section{Konstantinos Delis, John Robotis, Michalis Chronakis}

Metropolitan General Hospital, Athens, Greece

Zenker's diverticulum is an outpouching of the esophageal mucosa through the cricopharyngeal muscle at the Killian triangle [1]. Endoscopically, the bridge of pseudodiverticulum sits between the esophageal lumen and the pouch and consists of mucosa, submucosa and muscle [2]. The rationale is to ablate the septum as much as possible and to open the pouch.

A 64-year-old male was referred to our facility because of chronic dysphagia of solids. Gastroscopy along with a barium meal revealed a $2 \times 2.7 \mathrm{~cm}$, bilocular Zenker's diverticulum (Fig. 1). The patient asked for endoscopic treatment, carried out under general anesthesia using a conventional Olympus endoscope. A 16-French Levin tube was loaded over a guide wire to separate the esophageal lumen from the diverticulum. We rejected a diverticuloscope because of the small size of the diverticulum. A soft, straight, transparent cap (Olympus, Germany) was mounted on the endoscope tip to further improve the working view. With an Olympus Triangle Tip (TT) knife catheter, applying 35 Watts coagulation current (ERBE, Germany, generator), we cut the Zenker's septum from the saddle toward the bottom of the pouch in the middle line, applying careful traction movements of the TT knife, and stopped after approximately two thirds of the septum had been cut. We considered this sufficient to relieve the patient's symptoms, even for the bilocular type of diverticulum. A 12$\mathrm{mm}$ endoscopic clip was placed at the end of the cutting site to reduce the perforation risk [3]. The Levin tube was removed and the procedure was completed uneventfully, lasting approximately $35 \mathrm{~min}$. The patient was kept on nil by mouth over the next $6 \mathrm{~h}$, given broad spectrum antibiotics, and gradually started a liquid and soft food diet. There were no immediate or late complications. Three months later, the patient is symptom-free, although a follow-up barium meal depicted a small opacification at the ablated diverticulum (Fig. 2). To our knowledge, there is no randomized control study comparing diverticuloscopes versus caps regarding efficiency and complications. We clearly showed that a bilocular Zenker's diverticulum can safely be treated endoscopically by TT knife and cap.

Gastroenterology Department, Metropolitan General Hospital, Athens, Greece

\section{Conflict of Interest: None}

Correspondence to: Konstantinos Delis, II Merarchias 19, 18535

Peiraeus, Greece, e-mail: delkc1@gmail.com

Received 06 July 2016; accepted 10 July 2016; published online 28 July 2016

DOI: http://dx.doi.org/10.20524/aog.2016.0076

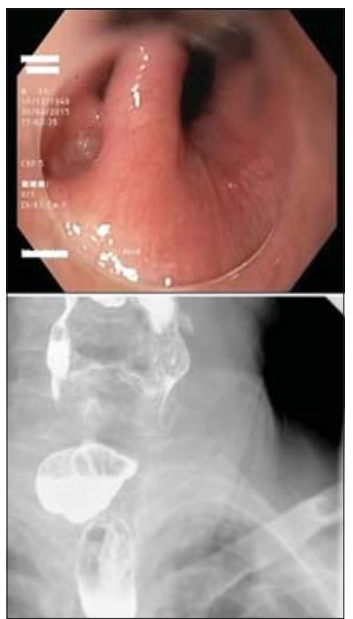

Figure 1 Endoscopic and radiological images of the bilocular Zenker diverticulum

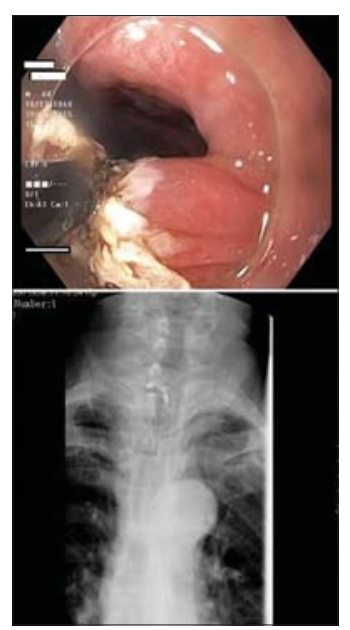

Figure 2 Endoscopic and radiological images of the cut diverticulum

\section{References}

1. Dzeletovic I, Ekbom DC, Baron TH. Flexible endoscopic and surgical management of Zenker's diverticulum. Expert Rev Gastroenterol Hepatol 2012;6:449-465.

2. Baron TH. Endoscopic treatment of Zenker diverticulum. Tech Gastrointest Endosc 2014;16:40-44.

3. Huberty V, El Bacha S, Blero D, Le Moine O, Hassid S, Devière J. Endoscopic treatment for Zenker's diverticulum: long-term results (with video). Gastrointest Endosc 2013;77:701-707. 